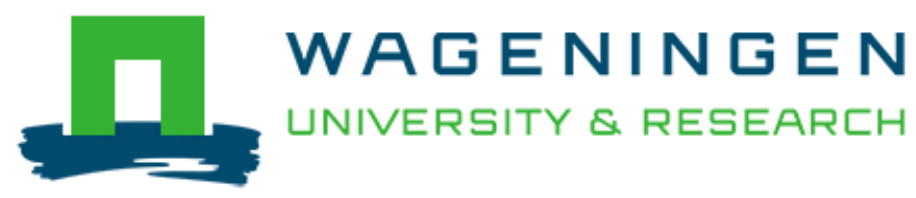

On integrating crowdsourced delivery in last-mile logistics: A simulation study to quantify its feasibility

Guo, X., Lujan Jaramillo, Y. J., Bloemhof-Ruwaard, J., \& Claassen, G. D. H.

This is a "Post-Print" accepted manuscript, which has been Published in "Journal of Cleaner Production"

This version is distributed under a non-commercial no derivatives Creative Commons (c) (1) @ $\Theta$ (CC-BY-NC-ND) user license, which permits use, distribution, and reproduction in any medium, provided the original work is properly cited and not used for commercial purposes. Further, the restriction applies that if you remix, transform, or build upon the material, you may not distribute the modified material.

Please cite this publication as follows:

Guo, X., Lujan Jaramillo, Y. J., Bloemhof-Ruwaard, J., \& Claassen, G. D. H. (2019). On integrating crowdsourced delivery in last-mile logistics: A simulation study to quantify its feasibility. Journal of Cleaner Production, 241, [118365].

https://doi.org/10.1016/j.jclepro.2019.118365

You can download the published version at:

https://doi.org/10.1016/j.jclepro.2019.118365 


\section{On integrating crowdsourced delivery in last-mile logistics: a simulation study to quantify its feasibility}

Xuezhen Guo

Wageningen Food \& Biobased Research

Amsterdam Institute for Advanced Metropolitan Solutions

Operations Research and Logistics Group, Wageningen University

Yngrid Jaqueline Lujan Jaramillo

Operations Research and Logistics Group, Wageningen University

Jacqueline Bloemhof-Ruwaard

Operations Research and Logistics Group, Wageningen University

G.D.H. Claassen

Operations Research and Logistics Group, Wageningen University 


\section{Abstract}

The fast-growing practice of e-commerce implies a strong increase in parcel deliveries, which in turn creates significant pressure on last-mile city logistics. Due to the important role the city transportation plays in energy use and greenhouse gas emission, effective last-mile solutions in cities must be developed to contribute to sustainability and a cleaner world economy. Crowdsourced delivery as an emerging "sharing economy" initiative can be an effective tool to mitigate the problems emerging from the last-mile city logistics. To valorise the benefits of crowdsourced delivery, a transition towards a hybrid city logistic system is required where crowdsourced delivery and the conventional delivery networks are closely integrated. Due to the lack of theoretical guidelines for crowdsourced delivery integration, this research develops a conceptual framework to facilitate last-mile city logistics transition adopting the multi-level socio-technical transition theory as the basis. The core of the conceptual framework is the "five basic principles" to be followed by stakeholders when designing intervening niche innovations at the current stage of system transition. To demonstrate the usability of the conceptual framework, an illustrative discrete event simulation study with specific settings that fits in with the current status of last-mile city logistics is conducted. Results show that incorporating crowdsourced delivery as a supplement to the conventional delivery network, following the five basic principles proposed by the conceptual framework can reduce the last-mile logistic costs. Moreover, the offline participation rate plays a key role in ensuring the feasibility of the new hybrid last-mile model. To conclude, the developed conceptual framework has a great potential of improving last-mile delivery in the era of e-commerce and having a critical scale of potential deliverer pool is the prerequisite for the successful application of crowdsourced deliveries.

Keywords: Sustainable City Logistics, Last Miles, Crowdsourced Delivery, E-commerce, Sharing Economy

\section{Introduction}

With rapid global urbanization, cities will become the predominating locations of human settlements by 2050 (Dye, 2008). Currently, some 80\% of European residents are living in cities (Vaghi and Percoco, 2011). Accompanying rapid urbanization, e-commerce has been increasing with the fast development of information and communication technologies (ICT) (Morganti et al., 2014). The widespread use of the internet and smartphones has boosted the growth of global business-to-customer (B2C) e-commerce. In 2015, the total sales of goods and services reached $\$ 2.2$ trillion, and it is expected to increase to $\$ 3.9$ trillion by 2020 (Ecommerce Foundation, 2016). The huge urban 
population coupled with fast-growing online shopping practice exerts significant pressures on the lastmile logistic system, which is one of the biggest challenges for city management. The streets are occupied more and more by parcel delivery vehicles and couriers. Although frequent urban delivery services bring significant convenience to our daily life, they also cause enormous sustainability issues. Paloheimo et al. (2016) state that transport is a highly relevant field for depletion of nature resources and environmental pollution because it accounts for nearly a quarter of global primary energy use and greenhouse gas (GHG) emissions (Moriarty and Honnery, 2013). In the European Union, 12\% of CO2 emissions are attributable to cars (European Commission, 2010). The increased number of delivery vans consume more fuel and emit more gases. In addition, these vans cause road congestion and slow down traffic flow, which indirectly increases fuel use and GHG emissions. Those problems will become even more serious in the future with the further development of e-commerce, particularly for B2C home deliveries. Taking Amsterdam, a city with a population of 800,000 inhabitants, as an example, the daily number of parcels entering the city is predicted to increase from 40,000 to over 100,000 in the next decade. Therefore, finding effective solutions to mitigate the pressure of last-mile logistics imposed by e-commerce will make a significant contribution to sustainability and a cleaner world economy.

In last-mile logistics, a conflict exists between the demand for delivery services and disruption to daily life. Citizens play two roles with conflicting interests. Acting as online shoppers, citizens prefer quick and flexible delivery services, which require more delivery vehicles and couriers to fulfil the mission. When acting as inhabitants, citizens prefer less crowded streets with fewer vehicles shuttling back and forth in the neighbourhood. The problem becomes even more complicated after adding the cost dimension. The highly demanding last-mile delivery service is known to be the most expensive part of the trip and could reach up to $75 \%$ of total logistics costs (Devari, 2017). However, because logistic service is highly intangible, consumers tend to take it for granted with weak willingness to pay more for better service (Galante et al., 2013). Such dilemmas make it difficult to improve last-mile logistics, as reflected in many failed last-mile city logistics projects (Gammelgaard, 2015). This also implies that conventional last-mile logistics solutions are no longer adequate, and innovative out-of-box thinking is needed.

Fortunately, the evolution of e-society not only brings problems but also potential solutions. Thanks to the advancement of ICT, we are now stepping into the age of a "sharing economy". Even though the term "sharing economy" has not yet been strictly defined, it is commonly used as an interchangeable term for "collective consumption" (Hamari et al., 2016). As a result, the scope of the sharing economy remains broad, including peer-to-peer renting, sharing, lending, selling and giving (Martin, 2016). As a disruptive business model, the sharing economy is expected to facilitate economic, social and environmental values, empower individuals and enable efficient utilization of resources (Martin, 2016). 
In a successful sharing economy, business cases range from car sharing (e.g. Uber) and bicycle sharing (e.g. Indego) to accommodation sharing (e.g. Airbnb) and household-item sharing (e.g. Peerby). Although most of the existing cases focus on "collective consumption" (targeting at the consumers), a group of new initiatives refer to the "sharing" concept in another context, i.e. "crowdsourced delivery" (CD), targeting the carriers/couriers that connect shops and consumers. $\mathrm{CD}$ is a new logistics concept that uses the crowd (i.e. ordinary people) as the workforce to deliver goods (Arslan et al., 2016). The concept is declared capable of combining goods deliveries with the journeys of ad hoc people to reduce delivery costs, shorten lead time, increase delivery flexibility, mitigate traffic-related problems and promote social networking activities (Hamari et al., 2016; Wang et al., 2016). However, there is also criticism regarding the validity of these statements. For instance, it is doubtful whether the CD model can really ensure lower logistics costs than the conventional logistics carrier model. The argument is that big carriers, such as UPS and DHL, are dealing with large volumes of goods and have the consolidation power to lower the costs per package delivery. As a contrast, CDs deal with individual delivery orders, which lack economies of scale. Such suspicions may explain the relative unsuccessfulness of the $\mathrm{CD}$ business model so far. Although a large number of CD start-ups or initiatives (such as Nimber, Paggy, Koorier) have emerged in recent years, none of them has grown into a large-scale company like Uber or Airbnb. Between 2013 and 2014, a few big companies such as Walmart, DHL and Macy's did launch several CD pilots but none of the pilots were scaled up or replicated in different cities.

Lack of knowledge on the CD business model is a major problem. Because $\mathrm{CD}$ has a relatively short history in business practices, only limited research in the literature addresses this topic. Arslan et al. (2016) developed a model to investigate the potential of using excess capacity of ad hoc drivers to deliver parcels. The study demonstrated that potential saving of driving distances up to $37 \%$ can be achieved. Archetti et al. (2016) conducted similar research to analyse a setting whereby occasional drivers are crowdsourced to complement a traditional delivery service, and they present a heuristic solution approach combining variable neighbourhood search and tabu search. Kafle et al. (2017) suggest a crowdsource-enabled system for urban parcel relay and delivery, where cyclists and pedestrians are crowdsourced to help truck carriers undertake the last-leg parcel delivery and the firstleg parcel pick up. The authors concluded that the new system can reduce the total travel miles and delivery costs. Li et al. (2014, 2016), Ghilas et al. (2013), Masson et al. (2014) and Fatnassi et al. (2015) addressed crowdsourcing of passengers to deliver parcels, either by taxi or by public transportation. These studies all demonstrate the great potential of improving the existing logistics system. Rougès and Montreuil (2014) conducted an exploratory study for the development of a framework to address $\mathrm{CD}$ on a higher level. The study introduces a typology of existing CD and presents a preliminary understanding of their value creation processes. The authors point out that future research should focus on better comprehension of the business models, including the challenges 
and success factors. They also observed the necessity of conducting simulation experiments to quantify the potential of CD. Finally, there is also a lag on conceptual framework development to guide the resolution of $\mathrm{CD}$ issues especially in the context of last-mile city logistics.

Other relevant recent publications concerning CD are the followings. Arslan et al. (2018) investigated the possibility of using ad hoc drivers to create a dynamic pickup and delivery network and concluded that the new network can make the last-mile delivery more cost-effective. Basık et al. (2018) looked into the fairness issue of $\mathrm{CD}$ for fair task allocation. They developed a new model for task allocation called "F-Aware" and claimed that it is a better way of task allocation compared to the traditional methods. Castillo et al. (2018) used a contingency theory lens to understand how crowdsourced logistics performs in terms of logistics effectiveness. Mario et al. (2019) proposed a CD initiative based on free-floating bike-sharing systems and claimed it a viable support and supplement for the local postal services. Dai and Liu (2019) developed a workforce capacity planning model for onlineto-offline logistics systems. They declared their research sheds light on cost control and efficiency improvement on O2O businesses. Punel et al. (2019) explored the push and pull factors affecting CD adoption using a structural equation method. The results revealed that $\mathrm{CD}$ is more likely for men, full time employed, younger respondents, and for areas of higher population density yet lower density of employment opportunities.

This paper aims to fill the gap between the increasingly prevailing CD practices and the shortage of relevant scientific knowledge on the feasibility of integrating $\mathrm{CD}$ into conventional delivery networks. It specifically focuses on integrating emerging $\mathrm{CD}$ initiatives into the last-mile city logistics from a system-transition point of view to create social-economic-environmental values. A conceptual framework based on the classical multi-level socio-technical transition theory is developed as the guidance to facilitate the transition. A simulation-based study is conducted for the illustration purpose on the developed framework.

The paper is structured as follows. Section 2 positions the CD models into the current last-mile city logistic system. In section 3, the conceptual framework is elaborated. In section 4, a simulation-based illustrative example is presented to demonstrate the usefulness of the conceptual framework and the potentials of CD innovations. Finally, discussion is conducted in section 5.

\section{Positioning CD models in the last-mile city logistics}


Last-mile city logistics is a complex system that consists of different delivery networks ${ }^{1}$ where the CD initiatives start to play an active role (Crainic and Montreuil, et al. 2016). The conventional delivery network consists of two basic logistic models: "shipper-operated" and "carrier-operated" models (See Figure 1). As the goods shipper, many big stores and supermarkets operate their own logistic networks to deliver products to the customers, while others outsource this service to professional carriers such as DHL and UPS. Both models have a top-down structure where the logistic professionals are instructed by the companies to perform the order deliveries.

\section{Insert Figure 1 here}

As to the CD network, there are three basic models in the market: peer2peer (peer to peer) delivery, $\mathrm{B} 2 \mathrm{C}$ (Business to consumer) shipping and $\mathrm{B} 2 \mathrm{C}$ neighbour receiving points. The peer2peer delivery refers to item (or package) deliveries between individuals using ad hoc deliverers. It works in the "Uber" way that the individual shipper who wants to deliver an item to the individual recipient posts a bid via a digital platform (e.g., a mobile phone App). A random person/cyclist/driver accepts the bid, makes the delivery and gets the compensation from the shipper. The application of peer2peer delivery is beyond the scope of city last-miles and can also be used for long-distance or even international shipments. A distinct feature of the peer2peer model is that there is no organization involved in the transaction, only individuals (Rougès and Montreuil, 2014). This is opposite to the B2C model which has the retailers or carriers involved (e.g. Amazon, Walmart, DHL and Macy's). With the B2C shipping model, companies try to find random deliverers to send their parcels in order to reduce delivery costs and lead time, especially at the last-mile stage (Dablanc et al., 2017; Arslan, et al., 2016). Both the peer2peer and B2C shipping models are focusing on parcel "shipping". However, another pain point for online shopping is parcel "receiving". The predominating e-fulfilment model in the market requires the online shoppers to personally attend parcel reception, which result in significant amounts of failed first-time deliveries (Song et al., 2013). It has therefore triggered the implementation of unmanned parcel receiving methods such as reception box, pick-up points, parcel stations with lockers, collection-and-delivery points (e.g., Morganti et al., 2014; Wang et al., 2014). However, the capacity of those methods are not enough to fulfil the demand of the quickly growing parcel businesses in cities. Hence, companies adopting the third CD model, i.e. B2C neighbour receiving points, have been emerging to fill the gap (e.g., Homerr and VIATM). This model crowdsources the at-home neighbours to receive the parcels for the absent online shoppers. The CD models by nature have more bottom-up aspects because they rely the business on autonomous individuals who can combine the parcel delivery service with their daily routines.

\footnotetext{
${ }^{1}$ Palletized product delivery (in a B2B environment) dealing with large-quantity transportation of bulky goods is not a subject for $\mathrm{CD}$, therefore out of the research scope. The last-mile city logistics referred to in this research is the one dealing with small-size package/parcel deliveries specifically from the B2C E-commerce practices.
} 
The B2C CD models have a larger potential in improving the last-mile city logistics than the peer2peer model because B2C deliveries account for the major volume of parcels in the cities. Therefore, the focus of this paper is on conceptualizing the transition of the urban parcel delivery system by incorporating $\mathrm{B} 2 \mathrm{C} \mathrm{CD}$ models ${ }^{2}$ into the conventional last-mile delivery network in the e-commerce environment. In the next section, a conceptual framework is developed to facilitate this transition.

\section{The conceptual framework for the transition of last-mile city logistics}

The fast growth of e-commerce imposes enormous challenges on last-mile city logistics (Savelsbergh and Van Woensel, 2016). As a result, a transition from the traditional top-down logistic system towards a hybrid system with more bottom-up aspects is demanded. A smooth transition requires the seamless integration of the $\mathrm{CD}$ initiatives into the conventional last-mile city logistic system with the engagement of individual citizens employing facilitating technologies. The bottom-up feature determines that such a transition is not only a matter of technological evolution but also social/practice transformation. In other words, it falls into the paradigm of the socio-technical transition.

As to the socio-technical transition, the most frequently citied work are Geels (2002 and 2011) which adopt a multi-level perspective on transitions. In this research, Geel's work is used as the theoretical foundation to develop the conceptual framework. The original Geel's framework is adapted to fit the context of last-mile city logistics transition with CD innovations (Figure 2).

\section{Insert Figure 2 here}

The conceptual framework includes three levels/layers: the socio-technical landscape, socio-technical regime and niche innovations.

The socio-technical landscape refers to the macro socio-technical context/factors that shape the surrounding environment of the transition. E-commerce pressure, trust and technology are the three factors considered in this research. The booming e-commerce is the ultimate exogenous driver to push forward the transition of last-mile city logistics. The pressure becomes larger and larger with the growth of online shopping practices which stimulates the last-mile city logistics restructuring with CD innovations. During this restructuring process, the prominent social factor that determines the success of CD integration is "trust" (Rougès and Montreuil, 2014). It does not only refer to the interpersonal trust between the crowdsourced deliverers and online shoppers but also the general confidence of the companies on the feasibility of the CD business models. The more trusts are in place, the more commitments from the practitioners can be expected and therefore the more likely a successful

\footnotetext{
${ }^{2}$ For easy notation, in the following text when referring to "CD model", it means the "B2C CD model".
} 
transition will happen. Technology is another factor that plays a key role in configuring the hybrid logistic system with CD innovations. It is necessary to point out that the technology referred in the "big arrow" is the "general technology" that differs from the "industry-specific technology" referred in the hexagon at the level of socio-technical regime. The "general technology" lays down the exogenous technical landscape to build "industry-specific technology". For example, the 5G technology can increase the internet speed by 100 times compared to the current $4 \mathrm{G}$, which will lead to a fundamental revolution for all industries. It is therefore a general technology. As a comparison, the Track \& Tracing technology for parcel delivery is a specific logistic technique whose development depends on the general technological landscape (e.g. 5G). It is therefore an "industry-specific" technology.

The existing socio-technical regime (i.e., the left-hand hexagon) refers to the current status of last-mile city logistics in which the conventional parcel delivery system has been long-established. The established six forces keep the socio-technical regime in its current steady state. The industrial players (i.e., retailers and third-party carriers) are used to their traditional way of doing the business and reluctant to move out of their comfort zone. The market/user preference has also the inertia. The online shoppers may feel uncomfortable with dramatic delivery service changes. The culture of being involved in CD has not yet been developed. It is still very unusual for people to actually participate in $\mathrm{CD}$, either as online shoppers or crowdsourced deliverers. The policies for city last-mile logistics are still based on the old system. Governments have not yet issued new supporting policies to facilitate CD development, neither via subsidies nor direct regulatory interventions. Finally, the science and technology development to address CD integration is still in the very initial stage. The current sociotechnical regime of the last-mile city logistics has been solidified, which makes the CD applications difficult to be adopted. Currently, there is hardly overlap between the conventional parcel delivery and CD networks.

To change the current socio-technical regime with $\mathrm{CD}$ and facilitate the transition towards the new regime (the hybrid system), successful niche $\mathrm{CD}$ innovations need to be developed to demonstrate their potentials and gradually break through the old regime. It is necessary to note that the niche innovations are not standalone units. They interact with the socio-technical landscape and regime (as indicated by the small arrow-lines). Therefore, when designing such innovations, one must take into account the development phase of the socio-technical landscape and regime to deal with the phasewise restrictions. Based on this philosophy, we come up with "five basic principles" (i.e., small-scale pilot, community-based approach, low added network complexity, low additional investment level, cofunctionality) that should be followed to design niche $\mathrm{CD}$ innovations at the current stage of last-mile city logistics transition. The five basic principles are supposed to help increase the chance of success for the niche $\mathrm{CD}$ innovations which ultimately contribute to the regime/system transition on the larger scale. 


\section{Small-scale pilot}

248 Given low social acceptance, a general lack of experience and low technological development for CD, it is hardly wise to start with large-scale business applications at this stage. Instead, small-scale pilot projects should be run to test the feasibility of specific $C D$ initiatives and cultivate a social technological culture with close involvement of practitioners and stakeholders. During this phase, lessons are learned and experiences are accumulated, which lays down the foundation for future upscaling.

\section{Community-based approaches}

To increase social acceptance and the related lack of trust, community-based approaches are the most appropriate. The "community" could mean a real social entity with spatial implications (e.g. neighbours in the same district) and could also mean a virtual group of people who are familiar to each other or share common values (e.g. a social media group, alumni associations). The main advantage of a community-based approach is that acquaintances or neighbours tend to trust each more than they trust strangers from outside the community. This is supposed to improve the willingness of CD participation. Moreover, it is easier for companies to deal with a community than with random individuals because the associated uncertainty is much smaller. In this sense, the community-based approach can help to increase the confidence of business practitioners in CD.

low added network complexity

Bounded by insufficient track and trace technology and low business acceptance for $\mathrm{CD}$, at this stage, $\mathrm{CD}$ innovations should avoid adding too much complexity to the existing delivery network to reduce the barriers for business adoption. For example, in an ideal situation, allowing transhipments between deliverers can enlarge the pool of potential CD deliverers. However, realizing that requires technological advancement of parcel track and trace systems, and the complexity of the delivery network would be significantly increased. Therefore, considering the current situation, the CD delivery network should be kept as simple as possible by avoiding complex routings, e.g. transhipments and multiple drop-offs by one crowdsourced deliverer.

\section{Low additional investment levels}

In order to reduce barriers for business application, the required level of additional investment for CD should be restricted at this stage of incorporation. Therefore, leveraging existing assets is more appropriate than investing in new assets. In terms of physical infrastructure, retailers can use the space in existing stores and supermarkets as distribution points instead of constructing new dedicated urban distribution centres. Regarding the IT infrastructure, collaborating with existing CD apps/websites 
may be an option to reduce the risk of capital lock-in for retailers compared with building up a selfowned digital platform dedicated to $\mathrm{CD}$.

\section{Co-functionality}

The principle of co-functionality is the core of a sharing economy. The aim of using CD in last-mile logistics is not only to reduce cost. It is encouraged more by social environmental considerations such as traffic congestion and GHG emissions. However, economic incentives do not always go hand in hand with social environmental motivations. Sometimes, they are even moving in opposite directions. For example, drivers using the Uber app could utilize their empty capacity for last-mile deliveries in cities. If they treat this service as a profitable business and proactively search for delivery opportunities, it will not help to solve the traffic problem because the delivery journeys are deliberately created. The principle of co-functionality requires the crowdsourced deliverer to combine the parcel delivery with an ex ante planned tour, instead of creating a completely new tour to earn money. In other words, CD initiatives motivated purely by economic incentives need to be avoided.

To quantitatively test the validity of the five "basic principles" and therefore demonstrate the usability of the conceptual framework, in the next section a simulation-based illustrative example of a niche CD innovation that fits the current situation of last-mile city logistics is presented.

\section{The simulation-based illustrative case study}

The simulation study investigates the feasibility of integrating CD with the conventional delivery method to tackle the challenges of e-grocery last-mile logistics.

e-Grocery retailers currently face high home delivery costs as a result of the requirement for special handling, cold storage, and short delivery time windows. These requirements lead to additional costs in transportation, labour, fleet of vehicles, and fuel consumption. High logistical costs are translated into high delivery fees, which most customers are unwilling to pay (Galante et al., 2013). High delivery fees, in turn, force e-grocers to establish longer time slots or inconvenient pick-up solutions to improve cost efficiency (Syndicate Plus, 2014; Nielsen, 2017). However, e-grocery shoppers usually want their products to be delivered as soon as possible and preferably delivered at home, thus prolonged delivery time windows or inconvenient pick-up settings can easily rule out their options on online groceries. Such issues hamper the growth potential of the e-grocery industry (Nielsen 2017; Galante et al., 2013; Huang and Oppewal, 2006) and offer opportunities for applying CDs.

The idea of the simulation study was to use outgoing traditional (offline) customers to deliver grocery parcels to their neighbour e-grocery shoppers in a dual-channel supermarket setting. Following the five basic principles for integrating CD in last-mile logistics, a hypothetical case that fits the current situation of last-mile logistics is presented. 
First, the case is a trial, which restricts its scope in a neighbourhood, consistent with the requirement of a small-scale pilot. Second, the case exploits the advantage of neighbour ties to increase the trust factor in CD. It accords with the notion of a community-based approach to valorize the benefits created by the "sense of community". Third, the case applies the simplest CD routing where the crowdsourced deliverer can only take one parcel for one drop in the neighbourhood, and no transhipments between deliverers are allowed. It therefore complies with the request for low added network complexity. Fourth, the case caters for the requirement of low additional investment level because the supermarket uses its existing store as the distribution point and no heavy investments are required to develop sophisticated and dedicated IT infrastructure for CD. Finally, the principle of cofunctionality is also followed because the crowdsourced deliverers are combining delivery with an existing journey.

The starting point of the delivery journey is the brick-and-mortar grocery retail store, represented by a hypothetical supermarket. The model follows the same logic as that presented in Arslan et al. (2016). The $\mathrm{CD}$ is seen as an order-delivery alternative where spontaneous deliverers replace the fleet of vehicles owned by the retailer or third-party logistics. The model rests on the collaboration of the supermarket's outgoing clients as deliverers. By leveraging their journey home trips, the supermarket serves online grocery orders for the neighbourhood.

Grocery parcels have to be delivered within a certain lead time or so-called time window. In Figure 3a, the time window ranges from the earliest departure time to the latest arrival time. Thus, it includes the matching and delivery time. The matching time is defined as the maximum time a grocery parcel can wait to be matched with a crowdsourced deliverer, and the last part includes the travel time and home delivery. To complete a single grocery parcel delivery, the deliverer has to make one stop at his/her neighbour's home before reaching his/her own final destination, represented by Figure $3 b$. After the task is accomplished, the deliverer receives a small economic compensation or a discount for their own shopping. In order to ensure that all e-grocery orders are fulfilled on time, the model includes conventional home delivery as a backup plan. That is, when a grocery parcel is unmatched at the latest departure time, the supermarket's vehicle will complete the task.

\section{Insert Figure 3 here}

\subsection{The simulation model}

The simulation model is developed in the Enterprise Dynamic programme (version 9; Enterprise Dynamics is a discrete event simulation software platform developed by INCONTROL Simulation Solutions to design and implement simulation solutions). The system consists of 22 atoms. As mentioned in the previous section, the retailer has a dual-channel setup. Hence, two sources are distinguished in this Enterprise Dynamic system. The first source corresponds to the supermarket 
atom, which represents the offline channel. At the exit, outgoing clients make the decision to participate or not in the crowdsourcing programme. Those who are willing to collaborate are considered as potential deliverers (PDs). PDs proceed towards the next atom, the pick-up point. Outgoing clients who are not interested in participating in this delivery programme leave the system immediately through the clients' home atom. In the second source, the website atom represents the online channel. After e-customers register and complete their purchases, the e-order is generated done. The processed e-order passes right away through the packing atom. The grocery parcel (GP) is then ready to be delivered within the time window assigned for the service.

PDs and GPs converge at the matching server. Two scenarios may occur: pair matched or unmatched. When the matched scenario happens (i.e. a PD and a GP appearing in the system simultaneously), the $\mathrm{CD}$ is carried out and the GP leaves the system after it reaches the neighbour's home. If no immediate match is available, the GP will stay in the system (i.e. waiting for a future match) until it reaches its latest departure time. If the unmatched scenario happens, the GP will be delivered by a backup vehicle from the supermarket.

Other assumptions taken into account in this simulation model are as follows:

- All customers and e-orders are independent. The elapsed time between two arrivals (inter-arrival time) for both the supermarket and the website sources follow a negative exponential distribution (NegExp).

- The time it takes to deal with a product (service time) follows a negative exponential distribution (NegExp).

- Orders get served one after the other (FCFS= first come, first served).

- Each crowdsourced deliverer can only deliver one parcel.

\subsection{The illustrative case formulation}

In this section, a representative supermarket is used as an example. The inputs are based on the literature, reports and from the website of a popular Dutch grocery retailer with on/offline grocery shopping (Ecommerce News, 2018).

\section{Neighbourhood size}

The Netherlands is a highly urbanized country, and on average it has 220 supermarkets per million inhabitants (Gorczynski and Kooijman, 2015). Therefore, for this case, it is assumed that the supermarket serves a neighbourhood population of 4550 inhabitants. 
Around 15\% (2.5 million) of Dutch people shop for groceries online (Gorczynski and Kooijman, 2015). Therefore, it is assumed that 683 of the 4550 inhabitants are shopping for groceries online. It is also assumed that online grocery orders can be delivered only from the 1476 regular-size stores owned by the most popular Dutch retailers with availability of on/offline grocery shopping (ah.nl, 2018; statista.com, 2018). Small stores have been excluded from this case study.

Supermarket's opening and peak hours

The supermarket is opened from 08:00 to 22:00 hours on weekdays (based on the information from a major Dutch on/offline grocery retailer). In reality, it can be observed that the flow of incoming clients is considerably higher after working time. To mimic this situation, a peak period of 2 hours is introduced from 17:00 to 19:00 hours when the number of visitors is doubled.

\section{Deliverers and e-order arrivals}

The visitor flows in the offline and online channels are estimated from the survey outcomes made by Syndicate Plus in 2014. According the survey, around 70\% of customers visit grocery stores weekly or more often and the remainder less than that or once a month. Taking an average figure, it is assumed that $70 \%$ of inhabitants visit the supermarket within a week.

With regard to the arrival of e-orders, around $70 \%$ of e-customers place an order once a month or less and the remainder purchase more frequently (e.g. weekly). On that basis, it is assumed that e-orders are placed monthly. Table 1 shows the calculations for the supermarket figures. As a result, it is expected that around 640 customers visit the supermarket and 85 e-orders are processed per day.

\section{Insert Table 1 here}

\section{Delivery time window}

The selected delivery lead time equals the time window offered by the most popular Dutch e-grocery retailer: 2 hours. The time is recorded immediately after an e-order is packed. By considering that inhabitants live within 10 minutes of the supermarket (Van der Slikke, 2015; Syndicate Plus in 2014), deliverers are expected to complete the $\mathrm{CD}$ within 15 minutes (ride time 10 minutes + door delivery 5 minutes).

\section{Crowdsourced and backup delivery fees}

The economic compensation assigned to the $\mathrm{CD}$ task is $€ 5$ (the rate used by TringTring in Amsterdam). The backup delivery fee is more expensive. The study bases this fee on the average cost of serving an e-shopper with home delivery in the Netherlands: $€ 13$ (Gorczynski and Kooijman, 2015). 
As stated above, the success of $\mathrm{CD}$ relies on fruitful recruitment of participants. According to the survey, more than $60 \%$ of respondents would be willing to participate in a CD (Punel and Stathopoulos, 2017). The survey does not indicate whether the $60 \%$ is online or offline participation willingness. A rough but plausible assumption has been made that the online participation rate should be higher than the offline participation.

In the default setting, it is assumed that $70 \%$ of the online grocery shoppers agree to being involved in CD. First, most e-grocery customers are aged between 25 and 44 years (Syndicate Plus in 2014), which is the same age group that leads acceptance of CD (Punel and Stathopoulos, 2017). Second, the level of acceptance is enhanced by the level of trust generated when the deliverer is someone who belongs to their neighbourhood. Finally, the supermarket's reputation gives customers the confidence that GPs are delivered on time and undamaged at a lower fee.

Regarding the offline channel, it is assumed that $20 \%$ of the outgoing clients could actually participate in $\mathrm{CD}$. The reason for considering a low percentage is that in practice, many factors can influence the real participation level of outgoing clients, even if they are willing to cooperate. For instance, the outgoing clients might not have enough time to complete the task at that moment, may be concerned about the size/weight of the GP, do not have adequate transport, etc.

The parameter values used in the base scenario of the simulation study are listed in Table 2. Moreover, the service time for the products in the atoms such as pick-up points, order generation, packing, matching, $\mathrm{CD}$ and backup vehicle have been set at values ranging from 1 to 5 minutes. Although the assigned values could differ in reality, those parameters are irrelevant for the comparison of different delivery systems.

\section{Insert Table 2 here}

\subsection{Experiment setting}

In total 36 experiments were carried out, including the base scenario and sensitivity analysis scenarios (Table 3). The parameters that are subject to the sensitivity analysis are presented in Table 4. The inter-arrival times (parameters 1,2,3) are calculated by backward induction based on the total number of deliverers and e-order arrivals (Table 2). To get the deliverer arrivals per hour, we distributed the total number equally (except for the peak period) through the 14 time slots that make up the supermarket schedule (Table 5). Similarly, e-order arrivals are distributed equally in the 12 hours of same-day service. The number of simulation runs conducted for each scenario was 100 . The average values for the output parameters are reported. 


\subsection{Simulation results}

\subsubsection{Base scenario}

The key performance indicators (KPIs) considered in the evaluation of the CD model are the matching rate and the total delivery costs. The matching rate is defined as the percentage of GPs that are served by the crowdsourced deliverers. Thus, the higher the matching rate, the more robust the CD integrated model is.

The reason why we selected those two KPIs is because they have close relationships with cleaner production and the feasibility of CD adoption. First, CD is by nature a more sustainable way of delivery in last-mile logistics (i.e. substantially less GHG emissions) as long as the principle of "cofunctionality" is followed, because combined grocery shopping reduces the total number of journeys required for traditional grocery shopping. As more combined grocery shopping journeys are performed by the crowdsourced deliverers, GHG emissions will reduce during the practice of grocery shopping. In this sense, the KPI "matching rate" (i.e. the percentage of parcels delivered by the crowdsourced deliverers) captures the aspect of sustainability (cleaner production). Second, economic feasibility is the key to ensure the acceptance of the CD concept by the businesses. If the integration of $\mathrm{CD}$ can reduce the total delivery costs, then the companies are more willing to adopt it and the goal of sustainability (cleaner production) can be realized.

Table 6 lists the default values of the six targeted parameters assigned to the base scenario. Table 7 shows the simulation results for the initial values. The matching rate achieved is around $69 \%$. Regarding the economic implications, delivering all GPs the conventional way would have cost $€ 1118$, and the cost for the hybrid delivery model was $€ 646$. That is, the introduction of the crowdsourcing concept allows savings of about $42 \%$. 


\subsubsection{Scenario I: Increasing crowdsourcing participation}

The first scenario deals with the variability of parameters 5 and 6, i.e. crowdsourcing participation of outgoing clients and e-grocery shoppers. As can be observed in Table 8, the values for the online participation rates vary from $70 \%$ to $100 \%$. In addition, these values were tested under different levels of offline crowdsourcing participation $(5 \%, 10 \%, 20 \%$ and $30 \%)$ to analyse their relationship and impact on the matching rate.

\section{Insert Table 8 here}

Table 9 presents the outcomes obtained for the first scenario. Two patterns can be observed. The first pattern is found when the offline participation rate ranges between $5 \%$ and $10 \%$. A great improvement in the matching rate is observed from around $35 \%$ to $64 \%$. From Figure 4 , it can be observed that increasing participation in the online channel does not have a big impact on the KPIs.

\section{Insert Figure 4 here}

\section{Insert Table 9 here}

The second pattern covers the experiments where the offline participation is $20 \%$ and $30 \%$. Here, the matching rate increases considerably. It starts at $69 \%$ and increases continuously when more ecustomers choose $\mathrm{CD}$. When the online participation is $100 \%$, the matching rates are around $100 \%$. This implies that almost all GPs can be delivered through CD, which would minimize the delivery costs substantially and lead to the highest savings rate, above $60 \%$ (in comparison with the conventional model).

Figure 5 plots the shortage or surplus of PDs at each participation level. The dashed line marks the tipping point of the $\mathrm{CD}$ model for this case study. It explains the presence of the two trends mentioned above. At lower levels of offline participation (5\% or 10\%), the PDs recruited are not sufficient to serve all GPs assigned to the CD mode. In contrast, when the offline participation reaches values equal to or above $20 \%$, there is a surplus of PDs.

\section{Insert Figure 5 here}

\subsubsection{Scenario II: Delivery time-window reduction}

The second scenario deals with changes in the values of parameters 4 and 5 (Table 4). The shortening of the parameter delivery time window to 1.5 and 1 hour is analysed at different offline crowdsourcing 
participation levels $(5 \%, 10 \%, 20 \%$ and $30 \%)$. Then, outputs are compared with experiments in which the delivery time window had an initial value of 2 hours (Table 10).

\section{Insert Table 10 here}

The main findings are that the reduction in the delivery lead time affects the performance measures of the CD model negatively, which is summarized in Table 11 and plotted in Figure 6. The impact is almost unnoticed when the delivery time window is shortened from 2 to 1.5 hours, especially for experiment runs $5 \mathrm{a}, 7 \mathrm{a}, 8 \mathrm{a}$. The negative performance of the matching rate could vary from $0 \%$ to $4 \%$. For the last time window resize (to 1 hour), there is a tendency towards a more pronounced deterioration in the overall performance. The matching rate deterioration ranges from $4 \%$ to $13 \%$ in comparison with the outcomes of scenarios where the delivery lead time is set at 2 hours.

\section{Insert Figure 6 here}

\section{Insert Table 11 here}

The decrease in the matching rate for shorter delivery time windows depends on the level of deliverer recruitment. The lower the number of PDs, the less likely the matching process becomes. For instance, for $70 \%$ online participation, the number of GPs assigned to the crowdsourced system is around 60 (85 $\times 0.70$ ). However, with $10 \%$ offline participation rate, only 48 and 40 GPs are successfully assigned to $\mathrm{CD}$ for the time windows of 1.5 and 1 hour, respectively. Conversely, at levels equal to or above $20 \%$ (tipping point) of offline participation, the number of GPs delivered by crowdsourced deliverers is around 60 and 55 for time windows of 1.5 and 1 hour, respectively.

Consequently, the costs savings are affected in the same way. Shortening of the delivery time window from 2 to 1 hour reduces the savings to $8 \%$ and $3 \%$ for offline participation of $10 \%$ and equal to or above $20 \%$, respectively.

\subsubsection{Scenario III: Online orders growth}

The last scenario investigates the impact of the future growth of online shopping. Inter-arrival times are altered for different offline crowdsourcing participation levels $(5 \%, 10 \%, 20 \%$ and $30 \%)$ as shown in Table 12. The growth rates for the online channel considered in this scenario are 5\%, $10 \%$ and $15 \%$, and the offline shoppers decrease accordingly, which results in a recalculated inter-arrival time.

According to the findings in Table 13, having more GPs to deliver with fewer PDs would not hamper the $\mathrm{CD}$ operation in all cases (no significant decline). When the offline participation is as low as $5 \%$ or $10 \%$, the number of PDs becomes insufficient to serve all the e-orders. For instance, in a $15 \%$ online 
growth rate scenario, the shortage causes a decrease of around $10 \%$ and $6 \%$ in the matching and cost saving rates, respectively. However, when the offline participation reaches $20 \%$ or above (tipping point), the increasing e-orders no longer put pressure on the $\mathrm{CD}$ model. As plotted in Figure 7, the matching rates for these cases remain almost unchanged.

\section{Insert Figure 7 here}

\section{Insert Table 12 here}

\section{Insert Table 13 here}

\section{Discussion}

\subsection{The conceptual framework}

In this paper, we have developed a conceptual framework to facilitate last-mile city logistics transition with the emergent $\mathrm{CD}$ models in the $\mathrm{B} 2 \mathrm{C}$ ecommerce context. The framework addresses the system transition with the basis that refers to the classical theory of multi-level socio-technical transitions. This framework pinpoints the key issues for CD integration and proposes five "basic principles" to be followed when designing the intervening CD innovations under the current socio-technical landscape and regime. It can be used as a high-level guideline to assist policy making towards a more sustainable and inclusive city logistics system. As the first work to promote CD integration in the last-mile city logistics system, this conceptual framework paves the way for further in-depth analyses on the potentials of different crowdsourced innovations that ultimately contribute to the system transition.

\subsection{The illustrative case study}

To demonstrate the usefulness of the conceptual framework, a simulation-based illustrative case following the guidance of the framework is presented. In that illustrative case, a crowdsourceddelivery model is proposed as a home-delivery alternative for e-grocery shopping. The case is built upon the five "basic principles" for niche innovations proposed by the framework where the rules of small-scale pilot, community-based approach, low added network complexity, low additional investment level, co-functionality are closely followed.

Based on the initial figures in the base scenario, the outputs revealed that an appreciable matching rate of approximately $70 \%$ can be achieved. The principal reason behind this is that food retailers have a large number of frequent visitors (weekly) compared with a smaller group of occasional e-customers (monthly). Hence, the number of PDs is substantially larger than the number of GPs to be delivered. Furthermore, matches between the destination of deliverers and GPs are more likely to happen because the delivery area is limited to the neighbourhood of the clients. 
Moreover, a more extensive evaluation of $\mathrm{CD}$ against different crowdsourcing participation levels was conducted to pinpoint a range of possible matching rates. In the best scenario, $100 \%$ of the deliveries of GPs can be accomplished by crowdsourced deliverers. On the other hand, in the worst case scenario, the matching rate barely reaches $34 \%$, leading to adoption of a hybrid delivery model (conventional + crowdsourced modes).

From the analysis of various scenarios, four main observations have been made. First, as some studies have already stated (Arslan et al., 2016; Van Cooten, 2016), the robustness of the CD model depends on satisfactory recruitment of participants, specially from the deliverer side. Our results confirm the importance of attracting a minimum level of PDs for the feasibility of CD operations. For this case study, the tipping point is at a level of $20 \%$ of offline crowdsourcing participation. When the number of PDs equals to or surpasses that level, it is possible to achieve favourable outcomes for any given level of online crowdsourcing participation. The full engagement of e-grocery shoppers and offline participation around $30 \%$ allow the best matching rate for the CD model $(100 \%)$.

In addition, a shorter delivery time window is beneficial, not only for online customers but also for the quality and integrity of GPs, especially when parcels contain perishable products. The CD model was tested for two cutbacks in the time windows: 1.5 and 1 hour. The results show that the matching rate responds to a reduction in delivery lead time, particularly when the time window is shortened from 2 to 1 hour. The worst outputs were identified when delivery time windows are reduced to 1 hour, and only $5 \%$ or $10 \%$ of the GPs are delivered by the crowdsourced deliverers. The performance measures of the model can be mildly affected when more PDs join the system. In general, applying a more responsive delivery policy is favourable for narrowing the time window to 1.5 hours. To apply a 1hour time window, the crowdsourcing participation level of outgoing clients has to be at least $20 \%$.

Third, experts predict a promising future for the e-grocery industry. Therefore, increasing growth is expected for the online channel, which translates to fewer customers visiting the supermarket. We evaluated the performance of the crowdsourced model when e-orders grew at rates of 5\%, 10\% and $15 \%$. The outcomes revealed two trends. An unfavourable picture arises when offline crowdsourcing participation barely reaches $10 \%$. Matching and saving rates decrease up to $10 \%$. However, when the system recruits higher levels of outgoing clients ( $20 \%$ or above), the CD model remains robust, and its performance measures are almost unchanged. Consequently, the growth of potential demand for the online channel is not as a significant threat to the proposed model as the unsuccessful recruitment of participants. 
Finally, although the simulation process yields promising results for the CD model, it is not possible to achieve a $100 \%$ matching rate. In those cases, the conventional system of home delivery must be used as a backup option to prevent the risk of leaving unmatched e-orders unattended. Hence, we suggest a hybrid delivery system, especially in the current (early) stage of CD implementations when participation rates in both channels may not reach the desired threshold levels.

\subsection{Conclusion}

Based on the simulation results, we derive the following conclusions:

- The integration of $\mathrm{CD}$ into existing last-mile delivery networks following the proposed five basic principles has great potential for improving last-mile logistics from both the economic and environmental points of view.

- To successfully implement $\mathrm{CD}$, a critical scale of potential delivers (i.e. the offline participation rate) is essential.

- CD cannot totally replace the traditional parcel delivery system, and therefore a hybrid delivery network is recommended.

\subsection{Limitations and Future Research}

There are also limitations for the developed conceptual framework and illustrative case study. Firstly, the conceptual framework is still quite abstract. It can be very useful to guide strategic plans of the last-mile city logistics system with $\mathrm{CD}$ initiatives but can not provide tactical or operational suggestions on specific issues faced by the practitioners.

Secondly, the case study is kept simple for illustrative purposes. Although extensive sensitivity analyses have been conducted, data and assumptions may not be sufficiently precise. Moreover, as a standalone numerical example, it cannot cover all relevant aspects of CD integration. However, the general pattern of the results is adequate and demonstrates the potential added value of CD for lastmile logistics.

Future research should concentrate on developing tactical and operational CD measures based on the proposed conceptual framework to provide practical suggestions and protocols for improvement of last-mile logistics. More qualitative and quantitative studies investigating different concepts of CD with various settings should be conducted to test the pros and cons of the hybrid system with CD integration. Finally, more marketing and sociology research should be conducted to find effective transition pathways for involving more participants to join $\mathrm{CD}$ and create the critical scale for businesses. 


\section{Reference}

Archetti, C., Savelsbergh, M., Speranza, M.G., 2016. The vehicle routing problem with occasional drivers. European Journal of Operational Research 254, 472-480.

Arslan, A., Agatz, N., Kroon, L., Zuidwijk, R., 2016. Crowdsourced delivery-a pickup and delivery problem with ad-hoc drivers. SSRN Electronic Journal, 1-29.

Arslan, A. M., et al. (2018). "Crowdsourced delivery-A dynamic pickup and delivery problem with ad hoc drivers." Transportation Science 53(1): 222-235.

Basık, F., et al. (2018). "Fair task allocation in crowdsourced delivery." IEEE Transactions on Services Computing.

Binetti, M., et al. (2019). "A Sustainable Crowdsourced Delivery System to Foster Free-Floating BikeSharing." Sustainability 11(10): 2772.

Castillo, V. E., et al. (2018). "Crowdsourcing last mile delivery: strategic implications and future research directions." Journal of Business Logistics 39(1): 7-25.

Crainic, T.G., Montreuil, B., 2016. Physical internet enabled Hyperconnected City logistics. Transportation Research Procedia 12, 383-398.

Dablanc, L., Morganti, E., Arvidsson, N., Woxenius, J., Browne, M., Saidi, N., 2017. The rise of ondemand 'Instant Deliveries' in European cities, Supply Chain Forum: An International Journal. Taylor \& Francis, pp. 203-217.

Dai, H. and P. Liu (2019). "Workforce planning for O2O delivery systems with crowdsourced drivers." Annals of Operations Research: 1-27.

Devari, A., Nikolaev, A.G., He, Q., 2017. Crowdsourcing the last mile delivery of online orders by exploiting the social networks of retail store customers. Transportation Research Part E: Logistics and Transportation Review 105, 105-122.

Dye, C., 2008. Health and urban living. Science 319, 766-769.

Ecommerce Foundation (2016). Global B2C E-commerce Report 2016. Available at: https://www.ecommercewiki.org/wikis/www.ecommercewiki.org/images/5/56/Global_B2C_Ecommer ce_Report_2016.pdf [Accessed 11 Oct. 2017].

Ecommerce News (2018). Ecommerce in the Netherlands - Ecommerce News. [online] Available at: https://ecommercenews.eu/ecommerce-per-country/ecommerce-the-netherlands/ [Accessed 11 Feb. 2018].

European Commission, 2010. Climate Action: Reducing CO2 Emissions from Passenger Cars. http://ec.europa.eu/clima/policies/transport/vehicles/cars/index_en.htm.

Galante, N., López, E.G., Monroe, S., 2013. The future of online grocery in Europe. McKinsey \& Company, 22-31.

Gammelgaard, B., 2015. The emergence of city logistics: the case of Copenhagen's Citylogistik-kbh. International Journal of Physical Distribution \& Logistics Management 45, 333-351. 
Geels, F.W., 2002. Technological transitions as evolutionary reconfiguration processes: a multi-level perspective and a case-study. Research Policy 31, 1257-1274.

Geels, F.W., 2011. The multi-level perspective on sustainability transitions: Responses to seven criticisms. Environmental Innovation and Societal Transitions 1, 24-40.

Ghilas, V., Demir, E., Van Woensel, T., 2013. Integrating passenger and freight transportation: model formulation and insights, Beta Working Papers WP 441. Technische Universiteit Eindhoven.

Gorczynski, T., Kooijman, D., 2015. The real estate effects of E-commerce for supermarkets in the Netherlands. The International Review of Retail, Distribution and Consumer Research 25, 379-406.

Hamari, J., Sjöklint, M., Ukkonen, A., 2016. The sharing economy: Why people participate in collaborative consumption. Journal of the Association for Information Science and Technology 67, 2047-2059.

Huang, Y., Oppewal, H., 2006. Why consumers hesitate to shop online: An experimental choice analysis of grocery shopping and the role of delivery fees. International Journal of Retail \& Distribution Management 34, 334-353.

Kafle, N., Zou, B., Lin, J., 2017. Design and modeling of a crowdsource-enabled system for urban parcel relay and delivery. Transportation research part B: methodological 99, 62-82.

Li, B., Krushinsky, D., Reijers, H.A., Van Woensel, T., 2014. The share-a-ride problem: People and parcels sharing taxis. European Journal of Operational Research 238, 31-40.

Li, B., Krushinsky, D., Van Woensel, T., Reijers, H.A., 2016. An adaptive large neighborhood search heuristic for the share-a-ride problem. Computers \& Operations Research 66, 170-180.

Martin, C.J., 2016. The sharing economy: A pathway to sustainability or a nightmarish form of neoliberal capitalism? Ecological Economics 121, 149-159.

Masson, R., Trentini, A., Lehuédé, F., Malhéné, N., Péton, O., Tlahig, H., 2017. Optimization of a city logistics transportation system with mixed passengers and goods. EURO Journal on Transportation and Logistics 6, 81-109.

Morganti, E., Seidel, S., Blanquart, C., Dablanc, L., Lenz, B., 2014. The impact of E-commerce on final deliveries: alternative parcel delivery services in France and Germany. Transportation Research Procedia 4, 178-190.

Moriarty, P., Honnery, D., 2013. Greening passenger transport: a review. Journal of Cleaner Production 54, 14-22.

Nielsen (2017). What's in-store for online grocery shopping: Omni channel strategies to reach crossover shoppers. Nielsen, January.

Paloheimo, H., Lettenmeier, M., Waris, H., 2016. Transport reduction by crowdsourced deliveries-a library case in Finland. Journal of Cleaner Production 132, 240-251.

Punel, A., Stathopoulos, A., 2017. Modelling the acceptability of crowdsourced goods deliveries: Role of context and experience effects. Transportation Research Part E: Logistics and Transportation Review 105, 18-38. 
Punel, A., et al. (2019). "Push and Pull Factors in Adopting a Crowdsourced Delivery System." Transportation Research Record: 0361198119842127.

Rougès, J.-F., Montreuil, B., 2014. Crowdsourcing delivery: New interconnected business models to reinvent delivery, 1st International Physical Internet Conference, pp. 28-30.

Savelsbergh, M., Van Woensel, T., 2016. 50th anniversary invited article—city logistics: Challenges and opportunities. Transportation Science 50, 579-590.

Song, L., Guan, W., Cherrett, T., Li, B., 2013. Quantifying the Greenhouse Gas Emissions of Local Collection-and-Delivery Points for Last-Mile Deliveries. Transportation Research Record: Journal of the Transportation Research Board, 66-73.

Statista. (2018). Netherlands: total number of Jumbo supermarkets 2011-2017 | Statistic. [online] Available at: https://www.statista.com/statistics/646377/total-number-of-jumbo-supermarkets-in-thenetherlands/.

Syndicate Plus (2014). The Online grocery shopper. Syndicate Plus, September.

Vaghi, C., Percoco, M., 2011. City logistics in Italy: success factors and environmental performance. City Distribution and Urban Freight Transport: Multiple Perspectives. Edward Elgar, Northampton, 151-175.

Van Cooten, C. (2016). Crowdsourced delivery the traditional delivery method reinvented. Eindhoven University of Technology.

Van der Slikke, T. (2015). Online retailing in the food industry. Wageningen University.

Wang, X., Zhan, L., Ruan, J., Zhang, J., 2014. How to choose "last mile" delivery modes for Efulfilment. Mathematical Problems in Engineering 2014.

Wang, Y., Zhang, D., Liu, Q., Shen, F., Lee, L.H., 2016. Towards enhancing the last-mile delivery: An effective crowd-tasking model with scalable solutions. Transportation Research Part E: Logistics and Transportation Review 93, 279-293. 


\begin{tabular}{|c|c|c|c|c|c|}
\hline \multicolumn{3}{|c|}{ E-order arrivals } & \multicolumn{3}{|c|}{ Deliverer arrivals } \\
\hline Total population & $16,900,000$ & & Neighb. Population & 4,550 & \\
\hline \multirow[t]{2}{*}{ Penetration online rate } & $15 \%$ & & Week visit rate & $70 \%$ & \\
\hline & $2,535,000$ & & & 3185 & per week \\
\hline Supermarket stores & 1476 & & & 640 & per day \\
\hline \multirow[t]{3}{*}{ e-orders per store } & 1717 & per month & & & \\
\hline & 429 & per week & & & \\
\hline & 85 & per day & & & \\
\hline
\end{tabular}

Table 1. Deliverer and e-order arrivals calculation.

\begin{tabular}{|c|c|}
\hline Neighbourhood Population & 4550 \\
\hline Opening hours & $08: 00-22: 00$ \\
\hline Peak hour period & $17: 00-19: 00$ \\
\hline Supermarket's visitors per day & 640 \\
\hline E-orders per day & 85 \\
\hline Delivery time-window & $2 \mathrm{hrs}$ \\
\hline Delivery time & $15 \min$ \\
\hline Crowdsourced-delivery fee & $€ 5$ \\
\hline Backup-delivery fee & $€ 13$ \\
\hline Online crowdsourcing participation \% & 70 \\
\hline Offline crowdsourcing participation \% & 20 \\
\hline
\end{tabular}

Table 2. The basic parameter values in the base scenario

\begin{tabular}{r|c} 
Scenarios & Parameter altered \\
\hline Base scenario & \\
Scenario I & $5 \& 6$ \\
Scenario II & $4 \& 5$ \\
Scenario III & $1,2,3$ \& 5
\end{tabular}

Table 3. General experiments design 


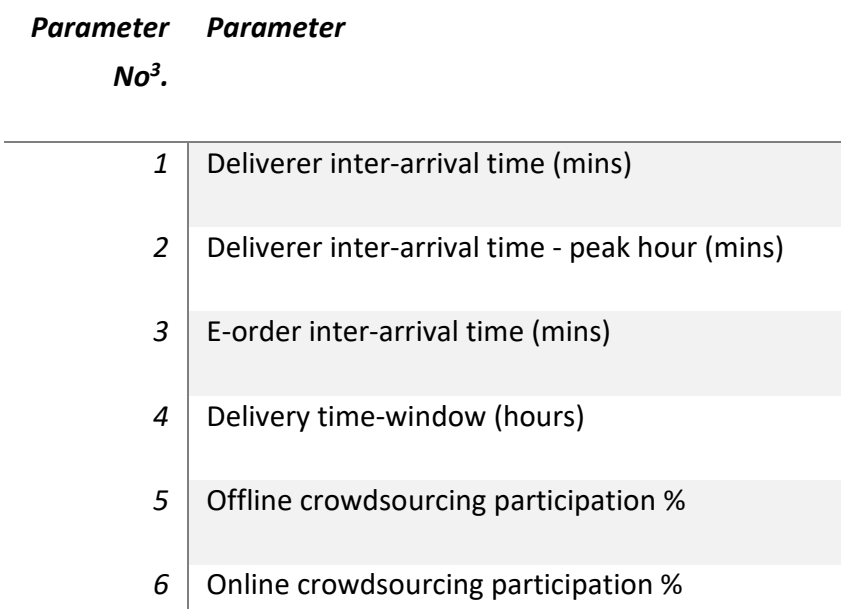

Table 4. Parameters subject to sensitivity analysis

\begin{tabular}{c|c|c|c|c|} 
& \multicolumn{2}{c}{ ARRIVAL RATE } & \multicolumn{2}{c}{ INTER-ARRIVAL TIME } \\
\hline OPENING HOURS & Deliverer & E-order & Deliverer & E-order \\
\hline 08:00 - 08:59 & 40 & 7 & 1.5 & 8.58 \\
09:00 - 09:59 & 40 & 7 & 1.5 & 8.58 \\
10:00 - 10:59 & 40 & 7 & 1.5 & 8.58 \\
11:00 - 11:59 & 40 & 7 & 1.5 & 8.58 \\
12:00 - 12:59 & 40 & 7 & 1.5 & 8.58 \\
13:00 - 13:59 & 40 & 7 & 1.5 & 8.58 \\
14:00 - 14:59 & 40 & 7 & 1.5 & 8.58 \\
15:00 - 15:59 & 40 & 7 & 1.5 & 8.58 \\
16:00 - 16:59 & 40 & 7 & 1.5 & 8.58 \\
17:00 - 17:59 & 80 & 7 & 0.75 & 8.58 \\
18:00 - 18:59 & 80 & 7 & 0.75 & 8.58 \\
19:00 - 19:59 & 40 & 7 & 1.5 & 8.58 \\
20:00 - 20:59 & 40 & ------------- & -1.5 \\
21:00 - 22:00 & 40 & & 1.5 & \\
& \hline 640 & 84 & 1.5 & \\
\hline
\end{tabular}

Table 5. Deliverer and e-order inter-arrival times 


\begin{tabular}{c|cccccc} 
Experiment/Parameter & $\mathbf{1}$ & $\mathbf{2}$ & $\mathbf{3}$ & $\mathbf{4}$ & $\mathbf{5}$ & $\mathbf{6}$ \\
\hline Base scenario & 1.50 & 0.75 & 8.58 & 2 & 20 & 70
\end{tabular}

Table 6. Parameter values for the base scenario.

\begin{tabular}{lc}
\hline Total Potential Deliverers & $\mathbf{1 2 9}$ \\
\hline Performing the crowdsourced-delivery & 59 \\
Unmatched deliverers & 71 \\
\hline Total Grocery Parcels & $\mathbf{8 6}$ \\
\hline Crowdsourced-delivery & 59 \\
Backup-delivery & 27 \\
\hline Matching Rate & $\mathbf{6 9 \%}$ \\
\hline Total Delivery Cost with conventional model (A) & $€ 1,118$ \\
\hline Total Delivery Cost with hybrid model (D=B+C) & $€ 646$ \\
\hline Crowdsourced-delivery cost (B) & $€ 295$ \\
Backup-delivery cost (C) & $€ 351$ \\
\hline Savings Rate with hybrid model = (A-D)/A & $\mathbf{4 2 \%}$
\end{tabular}

$\overline{T a b l e ~ 7 . ~ P e r f o r m a n c e ~ r e s u l t s ~ f o r ~ t h e ~ b a s e ~ s c e n a r i o ~(p e r ~ d a y) ~}$

\begin{tabular}{|c|c|c|c|c|c|c|}
\hline Experiment/Parameter & 1 & 2 & 3 & 4 & 5 & 6 \\
\hline Base scenario & 1.5 & 0.75 & 8.58 & 2 & 20 & 70 \\
\hline $1 a$ & & & & & 5 & 70 \\
\hline $1 b$ & & & & & 5 & 80 \\
\hline $1 c$ & & & & & 5 & 90 \\
\hline $1 d$ & & & & & 5 & 100 \\
\hline $2 a$ & & & & & 10 & 70 \\
\hline $2 b$ & & & & & 10 & 80 \\
\hline $2 c$ & & & & & 10 & 90 \\
\hline $2 d$ & & & & & 10 & 100 \\
\hline $3 a$ & & & & & 20 & 70 \\
\hline $3 b$ & & & & & 20 & 80 \\
\hline $3 c$ & & & & & 20 & 90 \\
\hline $3 d$ & & & & & 20 & 100 \\
\hline $4 a$ & & & & & 30 & 70 \\
\hline $4 b$ & & & & & 30 & 80 \\
\hline $4 c$ & & & & & 30 & 90 \\
\hline $4 d$ & & & & & 30 & 100 \\
\hline
\end{tabular}

Table 8: Experiment design for scenario I

\begin{tabular}{|c|c|c|c|c|c|c|c|c|c|c|c|c|c|c|c|c|}
\hline \multirow[b]{2}{*}{ Online participation } & \multicolumn{4}{|c|}{ Offline participation: $5 \%$} & \multicolumn{4}{|c|}{ Offline participation: $10 \%$} & \multicolumn{4}{|c|}{ Offline participation: $\mathbf{2 0 \%}$} & \multicolumn{4}{|c|}{ Offline participation: $\mathbf{3 0 \%}$} \\
\hline & $70 \%$ & $80 \%$ & $90 \%$ & $100 \%$ & $70 \%$ & $80 \%$ & $90 \%$ & $100 \%$ & $70 \%$ & $80 \%$ & $90 \%$ & $100 \%$ & $70 \%$ & $80 \%$ & $90 \%$ & $100 \%$ \\
\hline Total Potential Deliverers & 32 & 32 & 32 & 34 & 64 & 64 & 64 & 64 & 129 & 130 & 129 & 129 & 191 & 193 & 194 & 192 \\
\hline Performing the crowdsourced-delivery & 29 & 30 & 30 & 32 & 50 & 54 & 57 & 58 & 59 & 67 & 74 & 84 & 59 & 68 & 75 & 85 \\
\hline Unmatched deliverers & 3 & 2 & 2 & 2 & 14 & 10 & 7 & 6 & 70 & 63 & 55 & 45 & 132 & 125 & 119 & 107 \\
\hline Total Grocery Parcels & 85 & 85 & 85 & 85 & 84 & 85 & 83 & 86 & 86 & 85 & 84 & 85 & 85 & 86 & 84 & 85 \\
\hline Crowdsourced-delivery & 29 & 30 & 30 & 32 & 50 & 54 & 57 & 58 & 59 & 67 & 74 & 84 & 59 & 68 & 75 & 85 \\
\hline Backup-delivery & 56 & 55 & 55 & 53 & 34 & 31 & 26 & 28 & 27 & 18 & 10 & 1 & 26 & 18 & 9 & 0 \\
\hline Matching Rate & $34 \%$ & $35 \%$ & $35 \%$ & $38 \%$ & $60 \%$ & $64 \%$ & $69 \%$ & $67 \%$ & $69 \%$ & $79 \%$ & $88 \%$ & $99 \%$ & $69 \%$ & $79 \%$ & $89 \%$ & $100 \%$ \\
\hline Total Delivery Cost with conventional model (A) & 1105 & 1105 & 1105 & 1105 & 1092 & 1105 & 1079 & 1118 & 1118 & 1105 & 1092 & 1105 & 1105 & 1118 & 1092 & 1105 \\
\hline Total Delivery Cost with hybrid model $(D=B+C)$ & 873 & 865 & 865 & 849 & 692 & 673 & 623 & 654 & 646 & 569 & 500 & 433 & 633 & 574 & 492 & 425 \\
\hline Crowdsourced-delivery cost (B) & 145 & 150 & 150 & 160 & 250 & 270 & 285 & 290 & 295 & 335 & 370 & 420 & 295 & 340 & 375 & 425 \\
\hline Backup-delivery cost (C) & 728 & 715 & 715 & 689 & 442 & 403 & 338 & 364 & 351 & 234 & 130 & 13 & 338 & 234 & 117 & 0 \\
\hline Savings Rate with hybrid model $=(A-D) / A$ & $21 \%$ & $22 \%$ & $22 \%$ & $23 \%$ & $37 \%$ & $39 \%$ & $42 \%$ & $42 \%$ & $42 \%$ & $49 \%$ & $54 \%$ & $61 \%$ & $43 \%$ & $49 \%$ & $55 \%$ & $62 \%$ \\
\hline
\end{tabular}

Table 9. Simulation results for scenario I 


\begin{tabular}{|c|c|c|c|c|c|c|}
\hline Experiment/Parameter & 1 & 2 & 3 & 4 & 5 & 6 \\
\hline Base scenario & 1.5 & 0.75 & 8.58 & 2 & 20 & 70 \\
\hline $1 a$ & & & & 2 & 5 & \\
\hline $5 a$ & & & & 1.5 & 5 & \\
\hline $5 b$ & & & & 1 & 5 & \\
\hline $2 a$ & & & & 2 & 10 & \\
\hline $6 a$ & & & & 1.5 & 10 & \\
\hline $6 b$ & & & & 1 & 10 & \\
\hline $3 a$ & & & & 2 & 20 & \\
\hline $7 a$ & & & & 1.5 & 20 & \\
\hline $7 b$ & & & & 1 & 20 & \\
\hline $4 a$ & & & & 2 & 30 & \\
\hline $8 a$ & & & & 1.5 & 30 & \\
\hline $8 b$ & & & & 1 & 30 & \\
\hline
\end{tabular}

Table 10. Experiment design for scenario II

\begin{tabular}{|c|c|c|c|c|c|c|c|c|c|c|c|c|}
\hline \multirow[b]{2}{*}{ Delivery time } & \multicolumn{3}{|c|}{ Offline participation: $5 \%$} & \multicolumn{9}{|c|}{ ffline participation: 10 ffline participation: 20 ffline participation: 30} \\
\hline & $2 h$ & $1.5 \mathrm{~h}$ & 1h & $2 \mathrm{~h}$ & $1.5 \mathrm{~h}$ & 1h & $2 h$ & $1.5 \mathrm{~h}$ & 1h & $2 h$ & $1.5 \mathrm{~h}$ & 1h \\
\hline Total Potential Deliverers & 32 & 33 & 32 & 64 & 65 & 64 & 129 & 128 & 128 & 191 & 193 & 192 \\
\hline Performing crowdsourced-delivery & 29 & 29 & 24 & 50 & 48 & 40 & 59 & 59 & 54 & 59 & 58 & 55 \\
\hline Unmatched deliverers & 3 & 4 & 8 & 14 & 17 & 24 & 70 & 69 & 74 & 132 & 135 & 137 \\
\hline Total Grocery Parcels & 85 & 85 & 86 & 84 & 85 & 85 & 86 & 85 & 86 & 85 & 85 & 84 \\
\hline Crowdsourced-delivery & 29 & 29 & 24 & 50 & 48 & 40 & 59 & 59 & 54 & 59 & 58 & 55 \\
\hline Backup-delivery & 56 & 56 & 62 & 34 & 37 & 45 & 27 & 26 & 32 & 26 & 27 & 29 \\
\hline Matching Rate & $34 \%$ & $34 \%$ & $28 \%$ & $60 \%$ & $56 \%$ & $47 \%$ & $69 \%$ & $69 \%$ & $63 \%$ & $69 \%$ & $68 \%$ & $65 \%$ \\
\hline Total Delivery Cost with conventional model ( $\mathrm{A}_{\mathrm{i}}^{\prime}$ & 1105 & 1105 & 1118 & 1092 & 1105 & 1105 & 1118 & 1105 & 1118 & 1105 & 1105 & 1092 \\
\hline Total Delivery Cost with hybrid model ( $\mathrm{D}=\mathrm{B}+$ & 873 & 873 & 926 & 692 & 721 & 785 & 646 & 633 & 686 & 633 & 641 & 652 \\
\hline Crowdsourced-delivery cost (B) & 145 & 145 & 120 & 250 & 240 & 200 & 295 & 295 & 270 & 295 & 290 & 275 \\
\hline Backup-delivery cost (C) & 728 & 728 & 806 & 442 & 481 & 585 & 351 & 338 & 416 & 338 & 351 & 377 \\
\hline Savings Rate w/hybrid model $=(A-D) / A$ & $21 \%$ & $21 \%$ & $17 \%$ & $37 \%$ & $35 \%$ & $29 \%$ & $42 \%$ & $43 \%$ & $39 \%$ & $43 \%$ & $42 \%$ & $40 \%$ \\
\hline
\end{tabular}

Table 11. Simulation results for scenario II. 


\begin{tabular}{|c|c|c|c|c|c|c|}
\hline Experiment/Parameter & 1 & 2 & 3 & 4 & 5 & 6 \\
\hline 0 & 1.500 & 0.750 & 8.580 & 2 & 20 & 70 \\
\hline $1 a$ & 1.500 & 0.750 & 8.580 & & 5 & \\
\hline $9 a$ & 1.580 & 0.790 & 8.160 & & 5 & \\
\hline $9 b$ & 1.650 & 0.825 & 7.722 & & 5 & \\
\hline $9 c$ & 1.725 & 0.863 & 7.293 & & 5 & \\
\hline $2 a$ & 1.500 & 0.750 & 8.580 & & 10 & \\
\hline $10 a$ & 1.580 & 0.790 & 8.160 & & 10 & \\
\hline $10 b$ & 1.650 & 0.825 & 7.722 & & 10 & \\
\hline $10 c$ & 1.725 & 0.863 & 7.293 & & 10 & \\
\hline $3 a$ & 1.500 & 0.750 & 8.580 & & 20 & \\
\hline $11 a$ & 1.580 & 0.790 & 8.160 & & 20 & \\
\hline $11 b$ & 1.650 & 0.825 & 7.722 & & 20 & \\
\hline $11 c$ & 1.725 & 0.863 & 7.293 & & 20 & \\
\hline $4 a$ & 1.500 & 0.750 & 8.580 & & 30 & \\
\hline $12 a$ & 1.580 & 0.790 & 8.160 & & 30 & \\
\hline $12 b$ & 1.650 & 0.825 & 7.722 & & 30 & \\
\hline $12 c$ & 1.725 & 0.863 & 7.293 & & 30 & \\
\hline
\end{tabular}

Table 12. Experiment design for scenario III

\begin{tabular}{|c|c|c|c|c|c|c|c|c|c|c|c|c|c|c|c|c|}
\hline \multirow[b]{2}{*}{ Online orders growth } & \multicolumn{4}{|c|}{ Offline participation: $5 \%$} & \multicolumn{4}{|c|}{ Offline participation: $10 \%$} & \multicolumn{4}{|c|}{ Offline participation: $20 \%$} & \multicolumn{4}{|c|}{ Offline participation: $30 \%$} \\
\hline & 0 & $+5 \%$ & $+10 \%$ & $+15 \%$ & 0 & $+5 \%$ & $+10 \%$ & $+15 \%$ & 0 & $+5 \%$ & $+10 \%$ & $+15 \%$ & 0 & $+5 \%$ & $+10 \%$ & $+15 \%$ \\
\hline Total Potential Deliverers & 32 & 32 & 29 & 28 & 64 & 60 & 59 & 56 & 129 & 123 & 115 & 112 & 191 & 182 & 176 & 169 \\
\hline Performing the crowdsourced-delivery & 29 & 29 & 27 & 26 & 50 & 50 & 50 & 50 & 59 & 61 & 66 & 69 & 59 & 62 & 65 & 70 \\
\hline Total Grocery Parcels & 85 & 89 & 94 & 100 & 84 & 89 & 93 & 100 & 86 & 88 & 94 & 100 & 85 & 90 & 93 & 100 \\
\hline Crowdsourced-delivery & 29 & 29 & 27 & 26 & 50 & 50 & 50 & 50 & 59 & 61 & 66 & 69 & 59 & 62 & 65 & 70 \\
\hline Backup-delivery & 56 & 60 & 67 & 74 & 34 & 39 & 43 & 50 & 27 & 27 & 28 & 31 & 26 & 28 & 28 & 30 \\
\hline Matching Rate & $34 \%$ & $33 \%$ & $29 \%$ & $26 \%$ & $60 \%$ & $56 \%$ & $54 \%$ & $50 \%$ & $69 \%$ & $69 \%$ & $70 \%$ & $69 \%$ & $69 \%$ & $69 \%$ & $70 \%$ & $70 \%$ \\
\hline Total Delivery Cost with conventional model & 1105 & 1157 & 1222 & 1300 & 1092 & 1157 & 1209 & 1300 & 1118 & 1144 & 1222 & 1300 & 1105 & 1170 & 1209 & 1300 \\
\hline Total Delivery Cost with hybrid model ( $\mathrm{D}=\mathrm{B}+$ & 873 & 925 & 1006 & 1092 & 692 & 757 & 809 & 900 & 646 & 656 & 694 & 748 & 633 & 674 & 689 & 740 \\
\hline Crowdsourced-delivery cost (B) & 145 & 145 & 135 & 130 & 250 & 250 & 250 & 250 & 295 & 305 & 330 & 345 & 295 & 310 & 325 & 350 \\
\hline Backup-delivery cost (C) & 728 & 780 & 871 & 962 & 442 & 507 & 559 & 650 & 351 & 351 & 364 & 403 & 338 & 364 & 364 & 390 \\
\hline Savings Rate with hybrid model = (A-D)/A & $21 \%$ & $20 \%$ & $18 \%$ & $16 \%$ & $37 \%$ & $35 \%$ & $33 \%$ & $31 \%$ & $42 \%$ & $43 \%$ & $43 \%$ & $42 \%$ & $43 \%$ & $42 \%$ & $43 \%$ & $43 \%$ \\
\hline
\end{tabular}

Table 13. Simulation results for scenario III. 


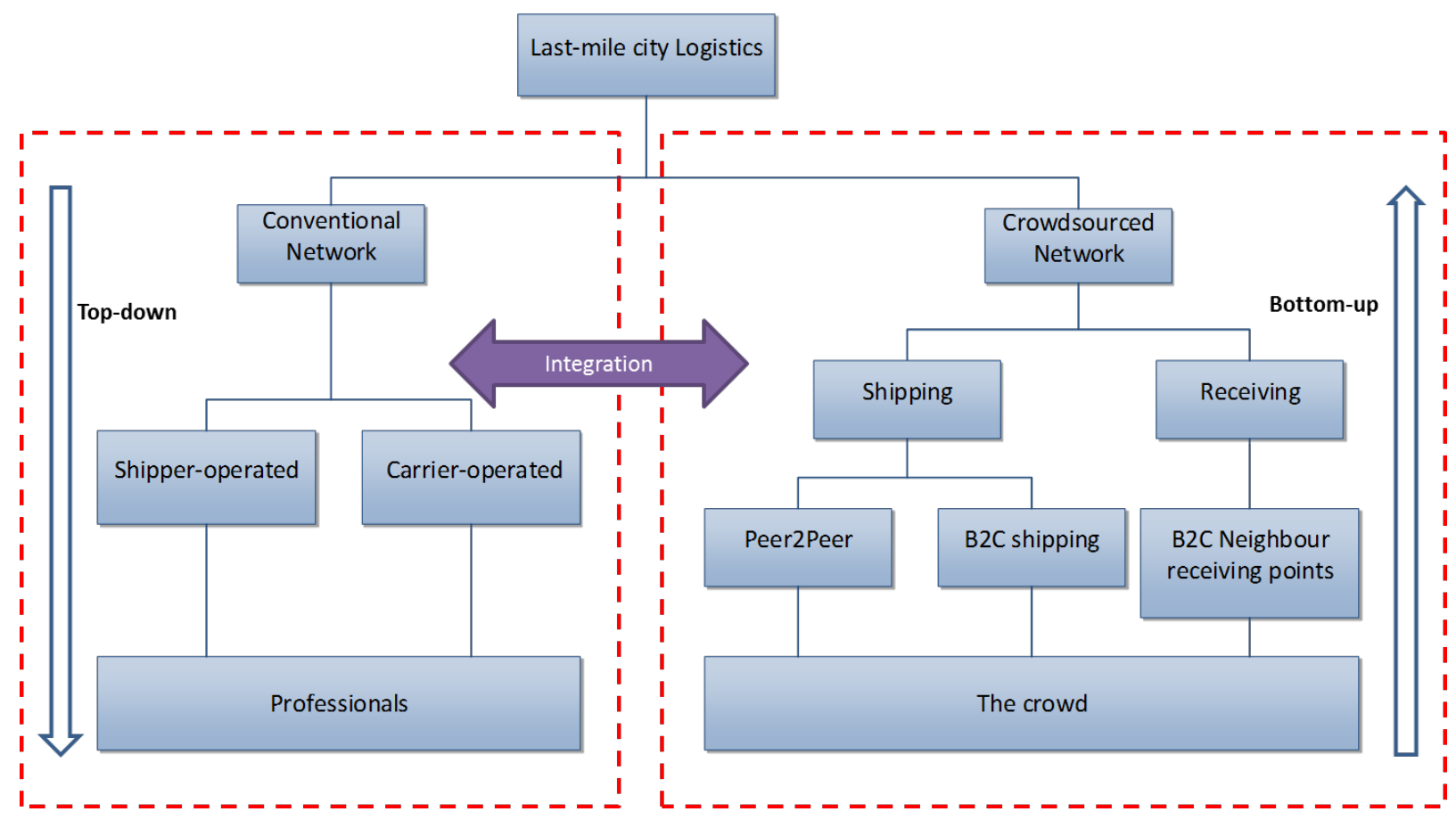

Figure 1. The last-mile city logistic system

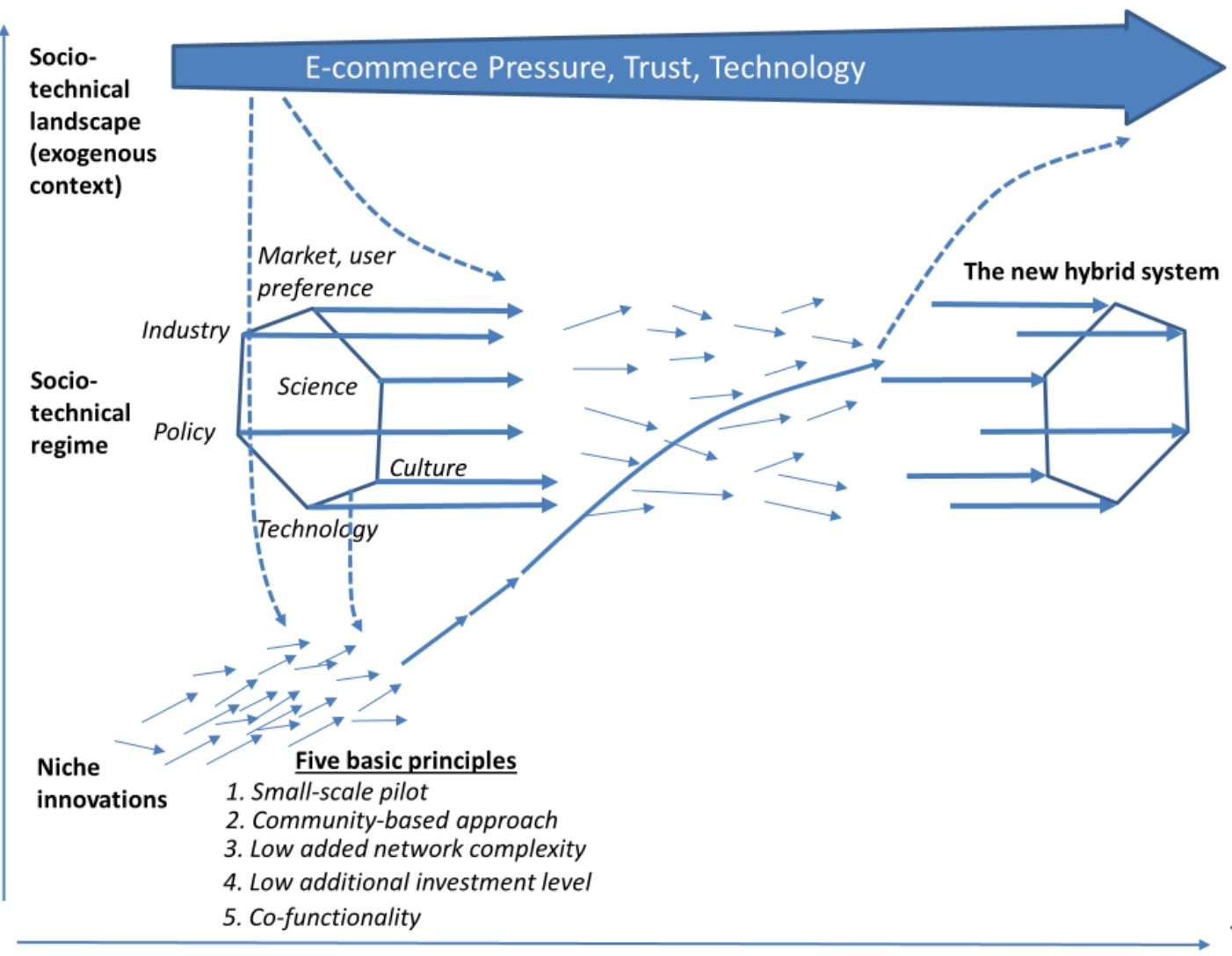

Figure 2. The conceptual framework for last-mile city logistics transition with CD innovations adapted from Geels (2011) 


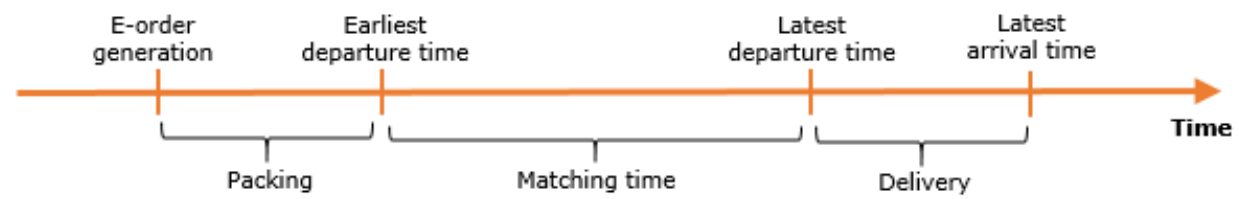

Figure 3a. Grocery Parcel delivery timeline adapted from Arslan et al. (2016)

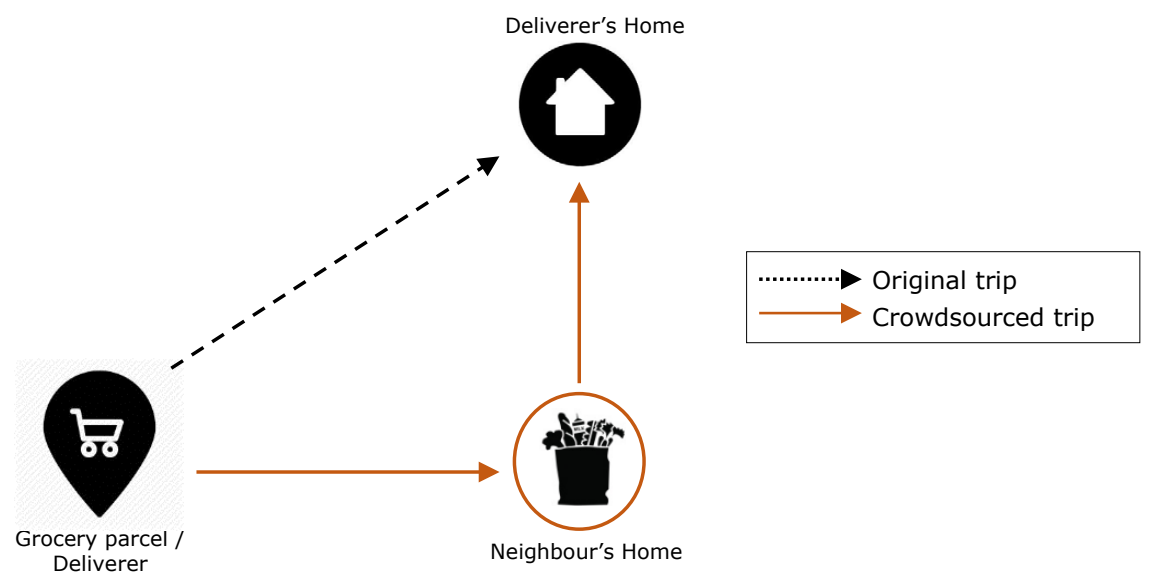

Figure 3b. The delivery scheme based on Arslan et al. (2016)

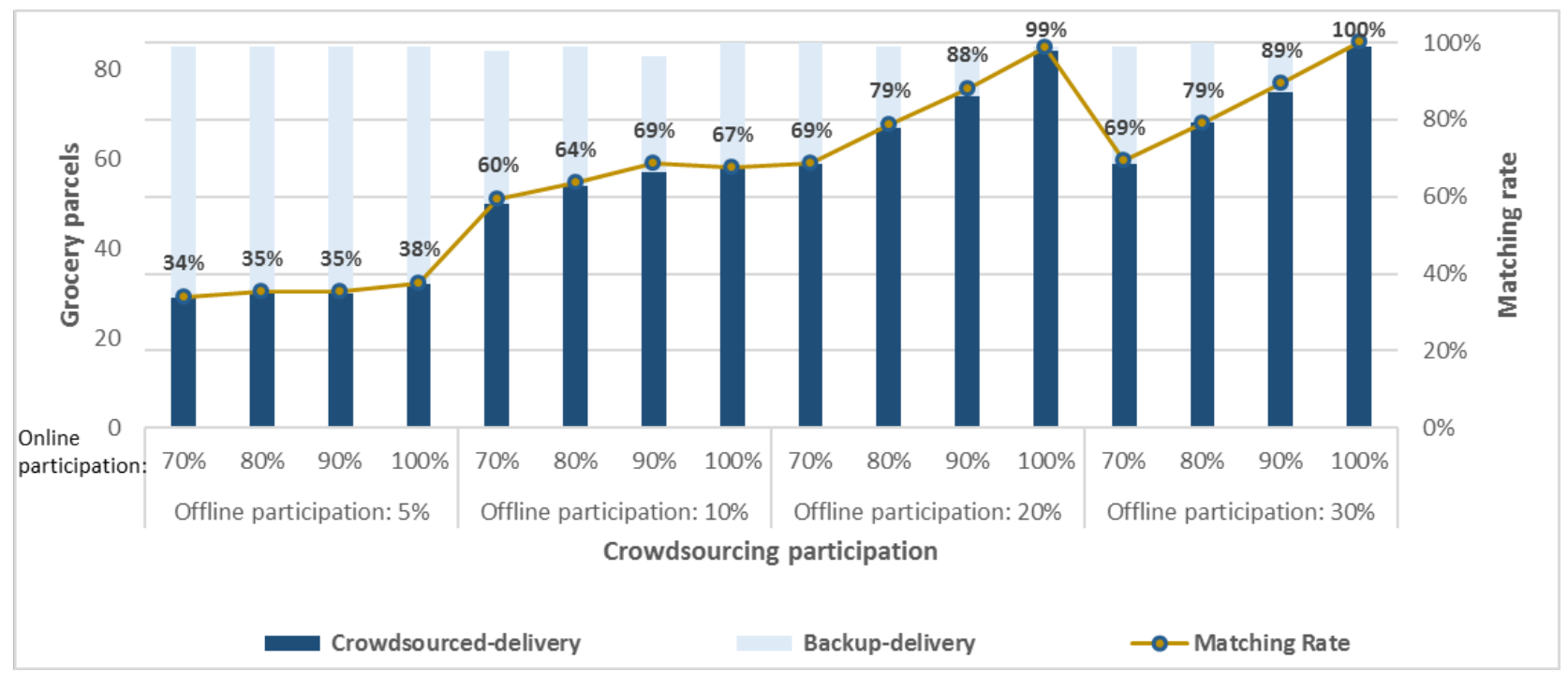

Figure 4. Matching rate performance per level of crowdsourcing participation 


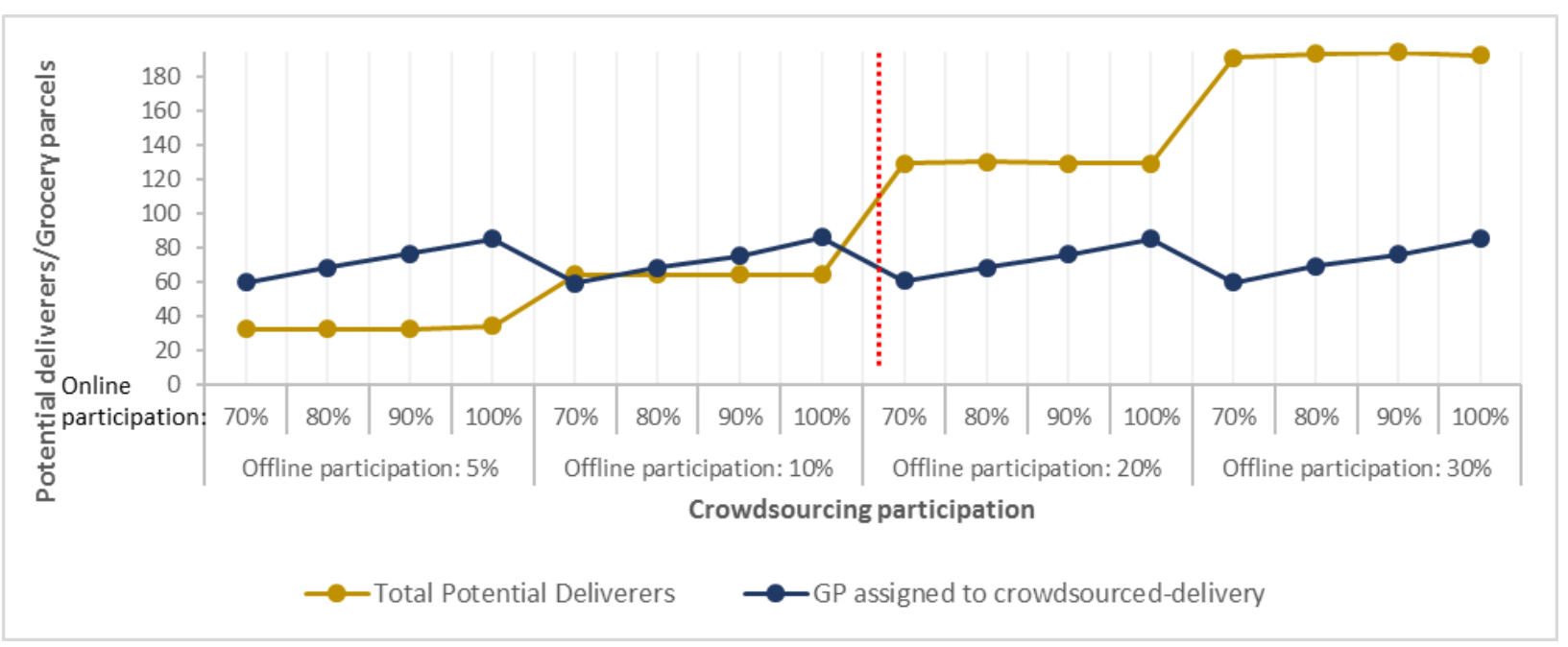

Figure 5. Shortage/surplus of potential deliverers

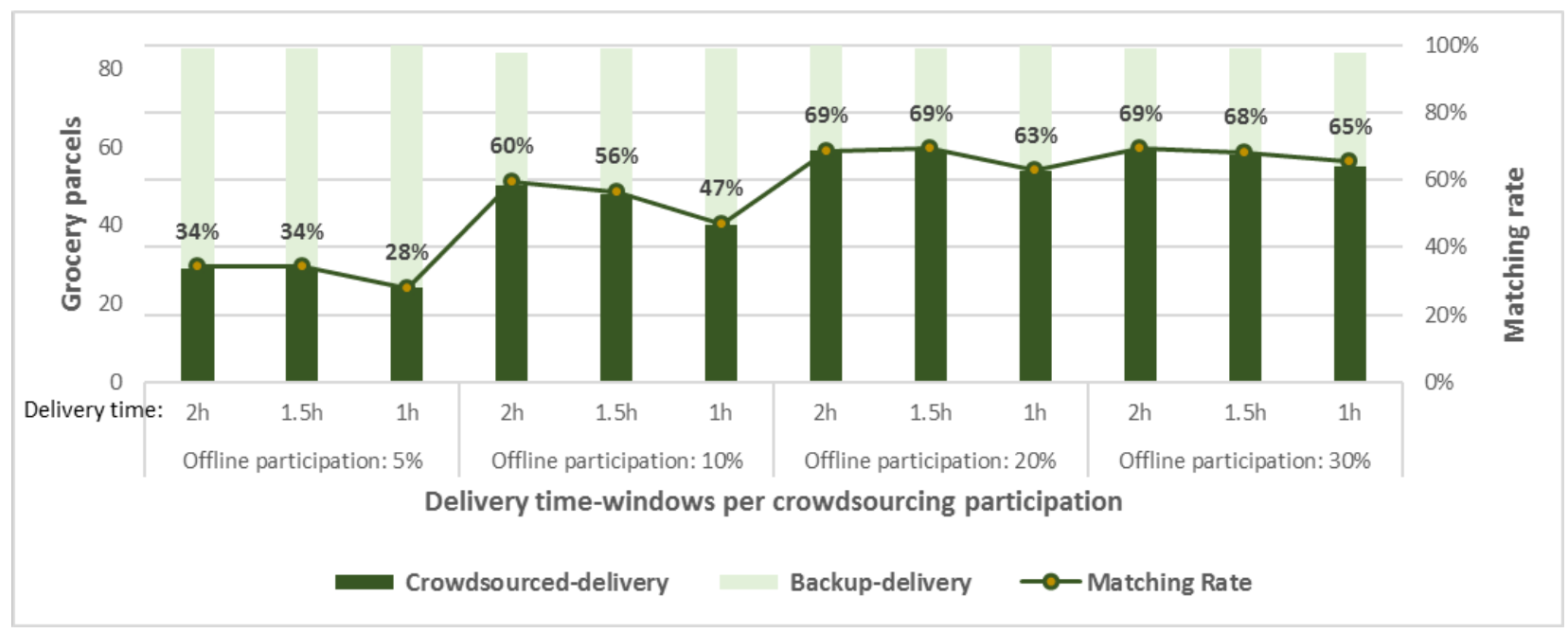

Figure 6. Matching rate performance per delivery time window.

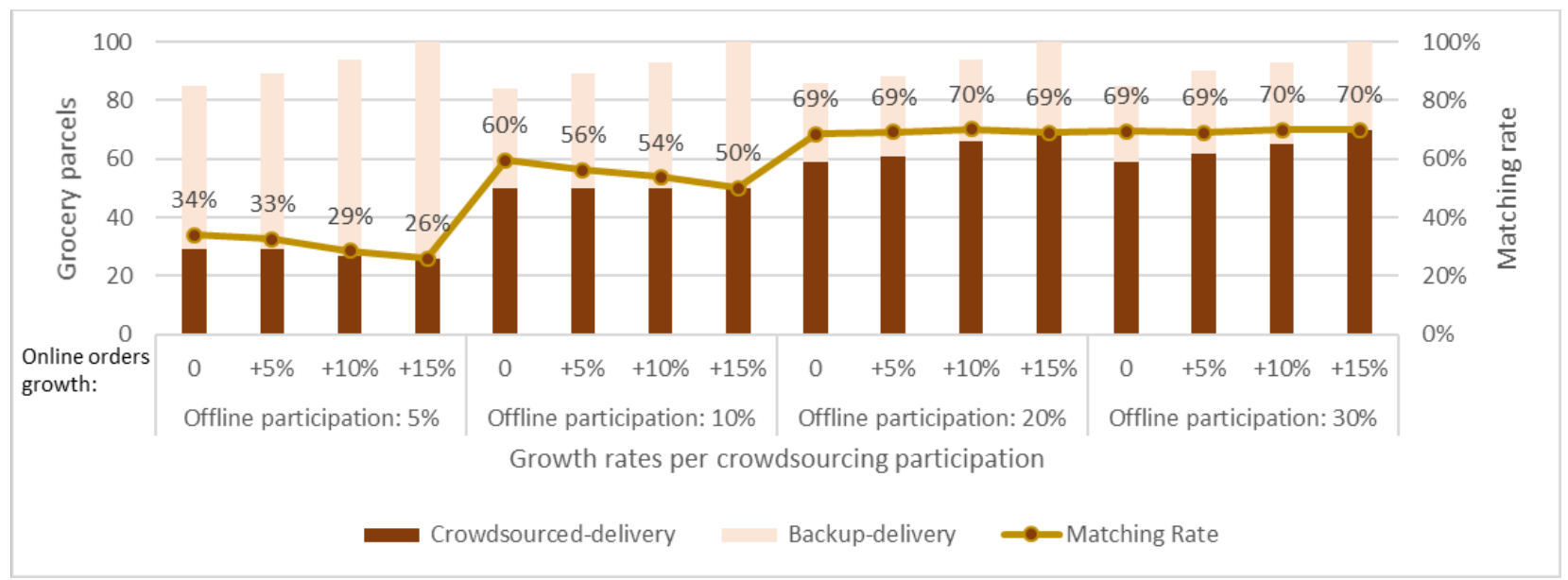

Figure 7. Matching rate performance for growth of the online channel 